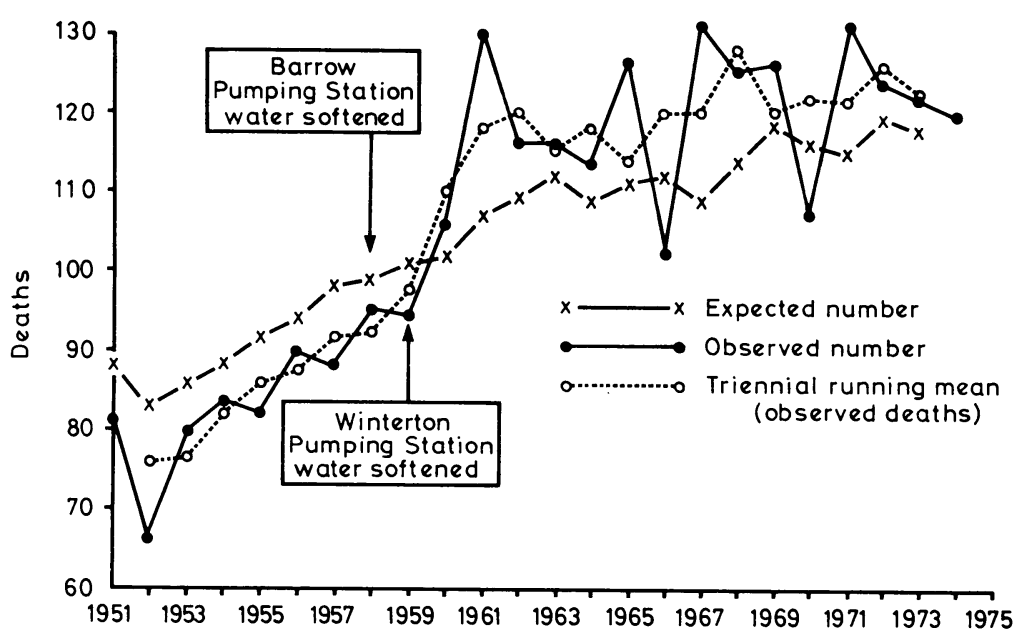

Male deaths, aged 45-64 years, from all causes in Scunthorpe Borough, 1953-75.

accompanying figure, the softening of the town's water supply was followed by an immediate rise in mortality to a level similar to that experienced in towns with soft water. If, as seems likely, these were cause and effect the mechanism must clearly be one which responds to the quality of water currently being used. It is not influenced by the mineral content of water or diet in previous years.

As you indicated in your leading article (4 February, p 264), identification of the water factor will not be easy. More than one element may be involved and the effect may be an indirect one. The mineral content of vegetables is profoundly affected by the hardness of the water in which they are boiled. This may affect their flavour and hence the amount of salt which people feel inclined to add. It is notable that while Dauncey and Widdowson ${ }^{4}$ found no significant difference in the urinary excretion of calcium or magnesium of residents in hard- and soft-water areas, they found that sodium excretion was significantly higher in residents in a soft-water area.

The answer to this riddle is unlikely to come from further epidemiological study. It will require a well-designed experiment such as a controlled trial of mineral supplements, the artificial "hardening" of a major water supply, or a combination of these to show whether calcium, magnesium, lead, or sodium is the "water factor." I believe that we should now be exploring the feasibility of fortifying cooking salt with calcium chloride and magnesium chloride. If the problems due to the hygroscopic nature of these salts could be overcome the issue of fortified salts to volunteers resident in soft-water areas might well throw light on this subject.

Scunthorpe Health District,
Scunthorpe, Humberside

J S ROBERTSON

' Crawford, M D, and Crawford, T, Lancet, 1969, 2,

699.
2 Anderson, T W, Le Riche, W H, and Mackay, J S, New England fournal of Medicine, 1969, 280, 805

${ }^{3}$ Robertson, J S, Community Health, 1977, 8, 226.

$\mathbf{1 , 7 1 1 .}$

\section{Birth trauma in vaginal breech delivery}

SIR,-Your leading article (11 February, p 320) rightly emphasises the need for gentleness and skill in breech delivery. I hope it will not encourage young obstetricians to resort to caesarean section for most women with a breech presentation, whether disproportion is present or not, as section must increase the maternal risk.

I cannot believe that injury to the fetal head is caused by the obstetrician's fingers: these injuries must surely be due to forcible traction on the fetal trunk, particularly when the head is badly flexed. Traction with the MauriceauSmellie-Veit method maintains flexion at any pelvic level and, I believe, is superior to the Liverpool or Burns-Marshall procedure, which tends to extend the head in relation to the pelvis. Gentle suprapubic pressure on the head also tends to keep the head flexed as it passes through the brim.

Lövset's manoeuvre for delivering extended arms is very popular, but if the head becomes tightly wedged in the pelvis because of the extended arms this manoeuvre can cause fracture dislocation of the cervical spine, and the classical method of bringing down the arms should be employed if the head does not easily rotate with Lövset's manoeuvre.

\section{London W4}

\section{HuMPhREY ARTHURE}

SIR,-Your leading article (11 February p 320) draws attention to the importance of injury to the occipital bone in delivery of the after-coming head. The work of Yates, stressing the vulnerability of the cervical spine and vertebral arteries, was not limited to breech deliveries, however; he chose 60 fetuses without regard to the method of delivery.

I believe that a similar investigation is overdue into the effects of compression of the occipital bone in vertex presentations Neurosurgical investigation of adults suggests that neurological presentations in later life may result from birth injury around the foramen magnum, particularly Chiari type 2 malformation and communicating syringomyelia. In a recent series ${ }^{1} 2$ of over 100 cases questioned at a mean age of 44 , over half of the patients had some history of birth abnormality big babies, long labours, application of forceps, and being first children in the birth order were all more common than in a control series. The reason for this association is unclear: haemorrhage around the cerebellum may cause adhesions, hydrocephalus may result and produce cerebellar herniation, and compression of the head by forceps or excessive moulding of the cranial vault may similarly press the brain downwards. It seems at least as likely that some of the many skeletal abnormalities around the foramen magnum found in association with cerebellar herniation may be related to osseous damage at birth. These include basilar invagination, "coarctation" of the foramen magnum, occipitalisation of the atlas, Klippel-Feil deformity, abnormal rotations of the atlas and axis, and concave deformities of the occipital bone.

To what extent is the occipital bone moulded during labour? How frequent are fractures at this site? There are obviously ethical difficulties in, for example, carrying out lateral skull radiography on newborn babies. If difficultlabour babies only were $x$-rayed, then the range of normals would not be defined. Perhaps ultrasonics might allow safe investigation of moulding around the foramen magnum and answer the question whether it can recover and whether any treatment at that age might aid recovery.

BERNARD WILLIAMS

Midland Centre for Neurosurgery

and Neurology,

Warley, W Midland

Williams, B, Lancet, 1977, 2, 51.

Williams, B, Zeitschrift für Kinderchirurgie und Grenzegebiete, 1977, 22, 533 .

SIR,-Your leading article on birth trauma in vaginal breech delivery (11 February, p 320) omitted to mention specifically the breech with an extended head. This situation is an absolute indication for delivery by caesarean section. It should be emphasised that in every breech pregnancy extension of the fetal head should be sought before delivery. Only in this way can the rare but very tragic complication of spinal cord transection be avoided.

I BLUMENTHAL

Department of Paediatrics

Leighton Hospital,

\section{Heritability of blood pressure}

SIR,-In your leading article on this subject (21 January, p 127) data from some studies on twins and families are quoted and commented on. It is concluded that both genetic and environmental factors must be at work; what is still in doubt is the relative size of each component. It is also assumed that an unknown proportion $(30-80 \%)$ of the variability of blood pressure found in different people is an inherited characteristic and that this genetic component appears to be polygenetic.

The study of cardiovascular risk factors, including blood pressure, and their genetic determination has been one of the main subjects of the research programme for the Swedish Twin Registry (containing 10000 same-sexed twin pairs) ever since its establishment in 1961. Lundman, ${ }^{1}$ in his study on 196 male and female twin pairs, found a closer intrapair similarity for monozygotic than dizygotic pairs, especially among females, with regard to both systolic and diastolic blood pressure. However, in a later study by Liljefors $^{2}$ on 96 male twin pairs no difference was noted between monozygotic and dizygotic intrapair variances. The latter results were interpreted as giving no support to the assumption that blood pressure is governed by heredity. Similar conclusions have also been reached in other twin studies conducted by Downie et $a l^{3}$ and Mathers et al. ${ }^{4}$ 
In a recent investigation on 31 male twin pairs cardiovascular reactions during stressful psychiatric interview were studied. ${ }^{5}$ It was found that intrapair variance did not differ between monozygotic and dizygotic pairs at rest either for systolic or for diastolic blood pressure, but during psychological strain the intrapair variances were significantly less within monozygotic than dizygotic pairs for both measures of blood pressure. These data imply that a significant genetic influence on the variability of blood pressure might first be revealed in stressful situations.

It was finally stated in your leading article that "clearly the best precaution a newborn baby can take over its arterial blood pressure and therefore its cardiovascular risk in later life is to choose its parents carefully." This hopeful piece of advice could be supplemented with another, more hopeful one: learn to cope with stressful situations.

Department of Medicine,

Serafimerlasarettet,

${ }^{1}$ Lundman, T, Acta Medica Scandinavica, 1966, supp

455.
2 Liljefors, I, Acta Medica Scandinavica, 1970, suppl

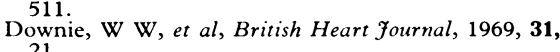

21.

Mathers, J A L, Osborne, R H, and de Geor
American Heart fournal, 1961, 62, 634.

de Faire, U, and Theorell, T, Programme of Second International Congress of Twin Studies, Washington, DC, 1977, p 24.

\section{Tuberculosis of the female genital tract}

SIR,-I read with interest your leading article on this subject (4 February, p 260). In East Anglia tuberculosis of the female genital tract appears to be excessively rare, possibly due to be absence of a significant immigrant population.

I would agree with you that laparoscopy is contraindicated if active tuberculous pelvic disease is suspected, but I think one should realise that in such populations as ours where there is no antecedent history of tuberculosis the diagnosis will be rarely made other than by laparoscopy. In 10 years I have diagnosed only three cases of tuberculosis, all by laparoscopy, which was carried out in two of them for infertility and in the third for abdominopelvic pain. In only one of the three, despite repeated attempts, was the responsible organism grown from endometrial curettings at the appropriate phase of the menstrual cycle. In the other two cases attempts to grow the organism from endometrial curettings failed, but it was grown from peritoneal biopsy specimens.

I would suggest that in future the diagnosis of genital tract tuberculosis in women is more likely to be made by laparoscopic examination than any other.

Cambridge

R E RoBINSON

SIR,-I wish to comment on your leading article on this subject (4 February, p 260). These comments are based on my personal experience of the management of more than 600 women with tuberculosis of the pelvic organs during the past 27 years.

I would agree that treatment of gynaecological tuberculosis is straightforward and that the drug regimens used so successfully for pulmonary lesions should also be applied to genital tuberculosis. Before one can assume that a patient has been cured by drug treat- ment, however, a long-term and thorough follow-up is essential. In some patients the tuberculous pelvic lesion recurs five or more years after the end of the drug course. The longest gap between treatment and recurrence in my own series is 19 years. Consequently it is entirely wrong to assume that a patient has been cured of her tuberculous condition after one or two post-treatment examinations.

In my most recent publication ${ }^{1}$ I discussed my experience of drug treatment of female genital tuberculosis during a 25-year period. In all groups, apart from those treated with the newer antituberculosis drugs, there was a substantial failure rate, the lowest being $12.3 \%$ in patients treated with streptomycin, PAS, and isoniazid for 18 months or two years. I have to date had no failures in the patients treated with streptomycin, ethambutol, and isoniazid or in the current group treated with rifampicin, ethambutol, and isoniazid. It is much too early, however, to compare these results with those in patients treated with earlier drug programmes.

No mention is made of the place of surgery in the treatment of tuberculosis of the female genital tract. The main indications for surgery are persistence or recurrence of the tuberculous condition, the development of pelvic masses, and the development of distressing symptoms particularly pelvic pain. In a previous article I presented a preliminary report on the indications for surgery. At that time $20 \%$ of my patients followed up required operative treatment. The results of pelvic clearance performed under antituberculosis drug cove were uniformly satisfactory. A further pape on this question is at present being prepared.

In your leading article it is stated that the outcome of drug treatment of gynaecologica tuberculosis is nowhere as well documented as it is in pulmonary disease. I am not in position to say whether or not this is so and gynaecological tuberculosis is certainly a fairly uncommon condition. I have, however, published more than 20 articles in this field in which details of a careful long-term followup are given.

Glasgow

ARTHUR M SUTHERLAND Sutherland, A $\mathrm{M}$, British fournal of Obstetrics and
Gynaecology, $1977, \mathbf{8 4}, 881$.
Sutherland, A M, Acta Obstetricia et Gynecologica
Scandinavica, 1965, 44, 163.

\section{Carbon dioxide-dependent}

\section{Escherichia coli}

SIR,-In view of the recent interest in carbon dioxide-dependent strains of Staphylococcus aureus (24 September, p 830) and Klebsiella spp (4 February, p 300) we would like to report the isolation of a $\mathrm{CO}_{2}$-dependent Escherichia coli $\mathrm{O} 75 \mathrm{~K}$ ?.

The initial isolate was from a midstream urine specimen containing large numbers of organisms on microscopy that failed to grow on cysteine-lactose electrolyte-deficient (CLED) medium incubated in air but grew when the urine was cultured on blood agar anaerobically, though not in air. It was thought at first to be an anaerobe. Isolation of a typica $E$ coli from a blood culture from the same patient taken two days after the urine culture prompted further investigation into the urinary isolate. The blood culture isolate had been recovered after subcultures on to blood agar incubated in $10 \% \mathrm{CO}_{2}$ and anaerobically. The organisms in the urine and blood were identical and failed to grow in a candle jar, though they grew well in a $\mathrm{CO}_{2}$ incubator and anaerobically (with $10 \% \mathrm{CO}_{2}$ ). An identical strain reappeared in the patient's blood and urine 26 days later, still $\mathrm{CO}_{2}$-dependent.

Such organisms are probably rare; this is the first we have encountered in 240 strains of $E$ coli isolated from blood and our procedure for the investigation of sterile bacteriuria and pyuria has never resulted in the isolation of $\mathrm{CO}_{2}$-dependent coliforms.

\section{SUSANNAH EYKYN} IAN PHILlips

Department of Microbiology,

St Thomas's Hospital Medical Schoo!, London SE1

\section{Needle tracheostomy for acute upper airway obstruction}

SIR,-In acute upper respiratory obstruction when intubation is not possible owing to lack of equipment or because the patient has complete laryngeal obstruction entrance to the respiratory tract through the cricothyroid membrane can be life-saving.

Dr T H Lee (4 February, p 281) mentions the use of a large-bore Medicut cannula introduced with its needle through the cricothyroid membrane, after which the needle and syringe are withdrawn and oxygen administered "over the cannula." In hospital in good light the cannula can be so used. In emergencies in general practice, particularly in bad light, there is always a possibility of the cannula disappearing into the trachea. It is therefore of practical advantage, having removed the syringe from the cannula, to detach the needle, take out the piston, and then reattach the barrel of the syringe to the cannula. This gives a wider aperture for the administration of oxygen. In the past a curved cricothyrotomy cannula with an introducer was quite frequently used in the treatment of acute respiratory obstruction. It is now coming back into use. The instrument available is an Abelson cricothyrotomy cannula and it is manufactured by Becton Dickinson and Co, an American firm whose UK office is in Wembley, Middlesex.

ROSEMARY H M ADAMS

Accident and Emergency Department,

Norfolk and Norwich Hospital,

Norwich

SIR,-Dr T H Lee gives an interesting account of needle tracheostomy (4 February, p 281), an operation which may indeed be life-saving. It is, however, not a safe one to rely on in general, as a needle or intravenous cannula is too easily blocked by blood or bronchotracheal secretions.

I share his rejection of formal tracheostomy. In an emergency it is too slow and too bloody. It should, however, be replaced (in my opinion) by laryngostomy, which is as quick as the needle method and permits tracheal suction, proper intubation, and positive pressure ventilation.

Laryngostomy was an operation devised in the days of laryngeal diphtheria and abandoned because of the disastrous scarring which developed at the operation site as a result of diphtheritic infection. If it is carried out according to the directions given in Accidents and Emergencies ${ }^{1}$ and not maintained for more than 48 hours, by which time it will be clear whether a formal tracheostomy is 